Acta Theriologica 45 (3): 353-365, 2000.

PL ISSN 0001-7051

\title{
Asymmetrical competition between the bank vole and the wood mouse, a removal experiment
}

\author{
Mauro FASOLA and Luca CANOVA
}

\begin{abstract}
Fasola M. and Canova L. 2000. Asymmetrical competition between the bank vole and the wood mouse, a removal experiment. Acta Theriologica 45: 353-365.

Experimental removal was conducted to test interspecific competition between the wood mouse Apodemus sylvaticus (Linnaeus, 1758) and the bank vole Clethrionomys glareolus (Schreber, 1780) that dominate the rodent communities in the forested biotopes through most of central Europe. Population density, body mass, reproductive condition, and habitat use were compared among two experimental sites (where one of the species had been removed) and one control site. The 5-year-study included pre-removal, removal, and post-removal periods. Reproductive condition was not affected by the density of the competitor or the conspecifics. Also, we did not detected any habitat shift that could be related to competitive release. However, the removal of wood mice strongly affected the population density of bank voles, but the removal of bank voles affected density of wood mice only slightly. Thus, we conclude that the competitive effect was asymmetrical.

Dipartimento di Biologia Animale, Università di Pavia, Piazza Botta 9, I-27100 Pavia, Italy, e-mail: fasola@unipv.it

Key words: Apodemus, Clethrionomys, competition, habitat, population
\end{abstract}

\section{Introduction}

Competition among species strongly affects many animal communities (Connell 1933, Schoener 1983, Gurevitch et al. 1992). For rodents, Grant (1972) early generalised the importance of competition, and Schoener (1983) showed that most studies on rodents, including Clethrionomys and Apodemus, ascertained at least some degree of competition. However, other studies suggested this importance has been over-emphasized (eg Kincaid and Cameron 1982, Galindo and Krebs 1985, Wolff and Dueser 1986, Scott and Dueser 1992).

Although interspecific competition among small mammals has been intensely studied during the past two decades, its role remains uncertain for many species assemblages and environments. Unequivocal evidence on the prevalence of compeition can only by provided by removal or exclusion experiments. For rodents in desert or dry environments, evidence of interspecific competition was found in exjeriments by Munger and Brown (1981), Thompson and Fox (1993) and Heske et al. (1994), but not by Abramsky and Sellah (1982). For herbaceous ecotones, 
competition effects were found by Busch and Kravetz (1992), and by Thompson and Fox (1993). For wooded areas of temperate regions, most removal experiments (Montgomery 1981, Gilbert and Krebs 1984, Wolff and Dueser 1986, Turner and Grant 1987, Scott and Dueser 1992) found no or slight competition within the rodent community, but others (Sekijima and Soné 1994, Dooley and Dueser 1996) did.

The wood mouse Apodemus sylvaticus (Linnaeus, 1758) and the bank vole Clethrionomys glareolus (Schreber, 1780) dominate the rodent communities in the lowland forests through Italy (Canova and Fasola 1991, Canova 1992) and, with the yellow-necked mouse Apodemus flavicollis, through most of central Europe (Corbet and Harris 1992). The realized niches of the bank vole and of the wood mouse differ in several components (Gurnell 1985). The bank vole is a typical forest species (Pucek 1983, Gurnell 1985), eats more leaves and green plant parts (Hansson 1985, Canova and Fasola 1993), and is more diurnal than the wood mouse (Wójcik and Wołk 1985). In northern Italy, diet, activity time, and microhabitat use differ between bank voles and wood mice (Canova 1993). This segregation of bank voles and wood mice along some dimensions of their niche is a necessary, albeit insufficient, indication that competitive interactions exist. It was suggested that these two species may compete for food and habitat (Gliwicz 1981, Ylönen 1990), particularly when their densities are high and food and space become limiting (Gurnell 1985). However, the lack of relationship between the abundance of one species and that of the other (Geuse and Bachau 1985), suggests that factors other than competition determine niche segregation. An experimental approach is needed to detect the existence of competition between the wood mouse and the bank vole, as already highlighted by Gurnell (1985). Gliwicz (1981) performed an experimental removal of the yellow-necked mouse and the bank vole, and found evidence of competitive release of the striped field mouse Apodemus agrarius, but the two species were not removed one by one, and the study lasted only seven months.

This paper describes the first selective experimental removal of the bank vole and the wood mouse, aimed to test the existence of competition between these two species. Population density, reproductive condition, body mass, and habitat use of the two species are compared for two sites where the other, possibly competing, species had been removed, and for one control site where rodent densities had not been manipulated.

\section{Material and methods}

This study was carried out in the "Bosco Negri" Nature Reserve, a mesic woodland near Pavia (NW Italy). The 35-ha woodland has experienced undisturbed growth for the past 60 years and is dominated by Quercus robur, Populus alba, and P. nigra at the overstorey level, by Crataegus monogyna, Robinia pseudoacacia, Fraxinus ornus, and Ulmus minor at the understorey level, and by Rubus sp. and Solidago sp. at the forbs and grass level. 


\section{Trapping scheme}

The experimental design included two treatments on removal-grids: selective removal of bank voles in one grid (thereafter called vole removal-grid) and selective removal of wood mice in a second grid (mouse removal-grid), and one control in the third grid (control-grid). Sampling was conducted using standard Capture-Marking-Recapture methods (CMR). During the pre-removal period (from February to April 1991), the rodents were simply captured, marked, and released. During the removal period (from May 1991 to April 1993), all captured bank voles and wood mice were eliminated from their respective removal grids and released at $>1 \mathrm{~km}$ distance. During the post-removal period (from May 1993 to October 1995), the populations were monitored without further manipulation.

The trapping grids were placed at three sites we selected, among 6 potential sites we had live trapped from October 1990 to January 1991, on the basis of the following criteria: (1) homogeneity in vegetation, litter depth and soil type, both within and between grids, to the eyes of the researchers; (2) presence of wood mice and bank voles in similar densities; (3) absence of other abundant species, only the Savi pine vole Microtus savii was occasionally trapped in the three grids $(0.7 \%$ of the total individuals captured); (4) distance among grids (>500 m) sufficient to preclude routine inter-grid movements by the rodents. Inter-grid movements were actually rare. Throughout our study, only $0.07 \%$ (bank vole) and $0.32 \%$ (wood mouse) of the individuals were captured in grids other than the one where they had been marked.

Trapping grids were square networks of 8 by 8 capture points, spaced at $10 \mathrm{~m}$ from each other, a distance suggested by Gurnell and Flowerdew (1990) for trapping in deciduous forests. When the total daily catches exceeded $50 \%$ of the traps, we provided two Sherman live traps at each capture point to reduce trap saturation. During capture sessions, the traps where baited with sunflower seeds and checked twice per day. Each capture session lasted 7 days per months and was carried out simultaneously in the 3 grids. Each captured individual was marked by toe-clipping, according to Twigg (1978), a technique that does not impair survival in small mammals (Braude and Ciszek 1998). Each captured individual was weighed (Pesola balances, $0.1 \mathrm{~g}$ approximation), and its age (adult, subadult, juvenile), sex and reproductive status were recorded following routine procedures (Gurnell and Flowerdew 1990). We used body mass of the adults as an index of body condition. The criteria adopted for discriminating adults were: full brown (bank vole) and brown and yellow fur (wood mouse), mass $>15 \mathrm{~g}$, and scrotal testes or perforate vagina during the breeding season; individuals previously captured in reproductive activity, and mass > 17.5 g during winter (Gurnell and Flowerdew 1990).

\section{Habitat assessment}

We adopted the approach proposed by Dueser and Shugart (1978), and used for our previous studies of mammal habitat use (Canova and Fasola 1991, Canova 1993). We measured the following six variables within a 5-m radius circle centered on each trap site: (1) litter depth: penetration of a graduated scale into the vegetal debris covering the soil $(\mathrm{cm})$; (2) fallen logs: their total number (diameter $>10 \mathrm{~cm}$ ) within the circle; (3) understorey density: total number of bushes and small trees (those with diameter from 2.5 to $24 \mathrm{~cm}$ at shoulder height) within the circle; (4) understorey size: average circumference of shrub stems and small trees, measured at shoulder height $(\mathrm{cm})$; (5) overstorey dersity: total number of trees (with diameter $>24 \mathrm{~cm}$ at shoulder height) within the circle; (6) overstorey size: tree average circumference at shoulder height $(\mathrm{cm})$.

\section{Data analysis}

Population data, obtained by CMR, were analysed using Capture 2.1, a software package that provides estimates for closed populations (White et al. 1982). Initially, population closure was tested for each 7-day capture session. Population closure was confirmed by Capture 2.1 for $80 \%$ of the sessions, ie in most cases population size did not change due to immigration, emigration, natality or motality through a session. Such population closure was expected, due to the short duration of a trasping session in relation to the life span and to the reproductive rate of the species.

Population size was then estimated for each capture session. Capture software analyses the Capture-Marking-Recapture data in the following four steps. (1) Computes capture probability for each 
individual. (2) Devises models that allow for capture probability variations due to behavioural, temporal, and heterogeneous factors. Eight models were tried, $\mathrm{M}_{0}$ assuming equal trappability for each individual, $\mathrm{M}_{t}$ allowing capture probability to vary with time, $\mathrm{M}_{b}$ allowing capture probability to vary with behavioural responses, $\mathrm{M}_{h}$ allowing capture probability to vary individually, and the four models resulting from all the permutations of $\mathrm{M}_{t} \mathrm{M}_{b} \mathrm{M}_{h}$. (3) Selects the BEST-FIT model. The model selected for the bank vole was $M_{h}$ for 20 trapping sessions, $M_{b}$ for 2 sessions, and $M_{0}$ for the remaining 32 sessions, and for the wood mouse it was $M_{h}$ for all sessions except 2 for which $M_{b}$ was selected. (4) Uses the BEST-FIT model to provide an estimator for population size.

To test the effects of competitor removal on the other species, we could not simply contrast the difference in population density between control- and removal-grids. The values of population time series are typically auto-correlated and hence difficult to test. Our time series were no exception, and their values were auto-correlated, both in the bank vole (correlation between population at month $\mathrm{n}$, and population at month $\mathrm{n}-1$ through the entire study, $r_{55}=0.67, p<0.001$ ) and in the wood mouse $\left(r_{55}=0.80, p<0.001\right)$. However, we are interested not in the population density, but only in their differences among grids. Therefore, we overcame the auto-correlation bias by calculating for each species the proportional difference between the control- and the removal-grids, ie for each month, the difference in population density between the two grids, divided by the population density of the control-grid. Dividing by the monthly population density neutralised the seasonal and annual variations in abundance. These proportional difference values were not auto-correlated; no significant correlation existed between the proportional difference at month $\mathrm{n}$ and at month $\mathrm{n}-1$, both in the bank vole $\left(r_{55}=0.11, \mathrm{~ns}\right)$ and in the wood mouse $\left(r_{55}=0.05, \mathrm{~ns}\right)$. This approach overcame the auto-correlation problem, but may have not overcome the data independence problem. However, this was the only possible approach in the absence of grid replications.

For body mass, we sought evidence of competitive effects by calculating the proportional difference in mass of adults in the control- and in the removal-grids. We calculated the difference between the monthly means in the two grids, and divided by the mean mass in both grids; division by the monthly mean mass neutralised seasonal and annual variations. In order to limit bias due to very small sample size, we retained the mass averages for the only months with $>5$ body mass measures for a given species and sex. This caution eliminated most data points for the bank vole from late 1993 to late 1994 when its population was low.

For the tests of the differences in habitat use by the two rodents, we considered only the point of first capture of each individual, and not its successive recaptures, in order to avoid the bias arising from possible attraction to bait and multiple captures of some individuals, or from trap avoidance and less capture of other individuals.

\section{Results}

\section{Population density}

Before removal, the densities of the two mammals were similar in their respective removal-grids and the control-grid. From March to June 1991, bank vole densities in the mouse removal-grid (mean $=106.5 \mathrm{ind} / \mathrm{ha}, \mathrm{SD}=26.7$ ) and in the control-grid $(90.6 \pm 17.7 \mathrm{ind} / \mathrm{ha})$ did not differ significantly ( $t$-test for paired samples: $t_{3}=-0.82$, ns). Likewise, wood mouse densities in the vole removal-grid $(71.0 \pm 4.8 \mathrm{ind} / \mathrm{ha})$ and in the control-grid $(58.1 \pm 15.4 \mathrm{ind} / \mathrm{ha})$ did not differ significantly $\left(t_{3}=-1.87, \mathrm{~ns}\right)$. This ensures that initial conditions were similar in the control- and the removal-grids.

The efficacy of our experimental removal was evaluated by comparing the abundance of each species in its respective removal-grid, with its abundance in the control-grid during the same capture sessions (Fig. 1a). The number of removed 
individuals remained high during the first 2 months of removal, when it averaged $88 \%$ (wood mouse) and 59\% (bank vole) of the minimum number alive (MNA) in the control-grid. After these first two months, the number of rodents removed from their respective removal-grids decreased and remained constant throughout the rest of the removal period, during which it averaged 57\% (wood mouse) and 26\% (bank vole) of the MNA in the control-grid. This constancy is shown by the absence of significant trends (see the two regression lines in Fig. 1a) in the ratio removed/MNA, both for the bank vole $\left(r_{19}=0.15, \mathrm{~ns}\right)$ and for the wood mouse $\left(r_{19}=0.06, \mathrm{~ns}\right)$. On the other hand, the ratio females:males among the removed mammals decreased throughout the removal period in both species (Fig. 1b); despite much variation among months, the correlation was significant for both the bank vole $\left(r_{21}=0.51, p\right.$ $<0.05)$ and the wood mouse $\left(r_{21}=0.56, p<0.05\right)$. The sex ratio in the removal grids decreased from the initial $1: 1$ in both species, to about 0.3 females: 1 male (wood mouse) and to about 0 females: 1 male (bank vole) during the last months of removal (Fig. 1b). We conclude that our experimental removal decreased substantially the density of the two species. Their abundance in the removal grid was decreased to about two-thirds of the non-manipulated population in the control-grid for the wood mouse, and to about one-third for the bank vole; this decrease affected particularly the females.
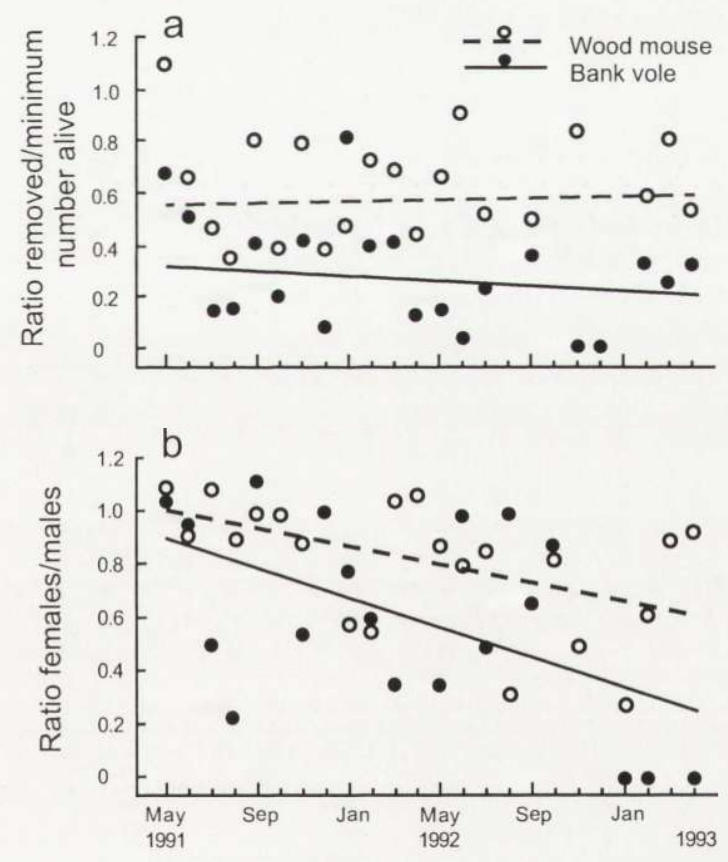

Fig 1. (a) Ratio between the number of removed bank voles and wood mice in their respective renoval-grids, and the minimum number alive in the control-grid. (b) Ratio females:males among the removed bank voles and wood mice. Best-fit regression lines are shown for each species. 


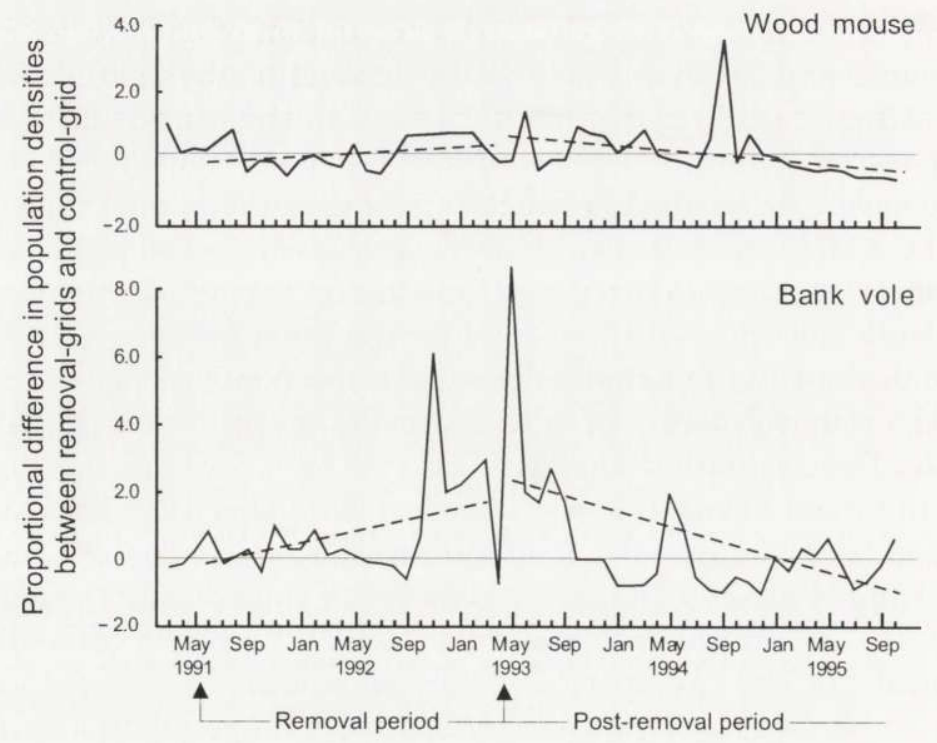

Fig. 2. Trends in population densities compared between removal-grids and control-grid. Separate regression lines are shown for the removal and the post-removal periods.

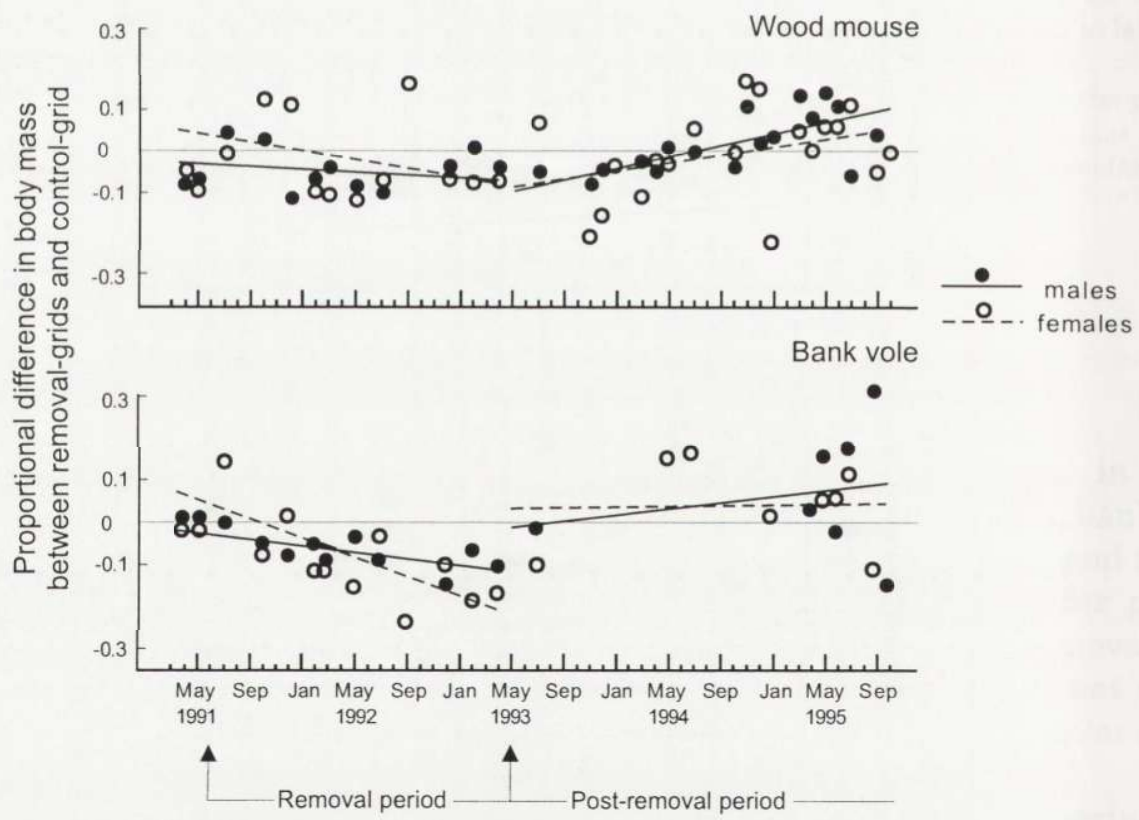

Fig. 3. Changes in body masses compared between removal-grids and control-grid. Separate regression lines are shown for males and females, and for the removal- and the post-removal periods. 
Competitive effects were supported if the population of one species increased in relation to competitor removal. During the removal of the possible competitors, wood mice increased very slightly in comparison to the control-grid (Fig. 2), and non-significantly $\left(r_{23}=0.31, \mathrm{~ns}\right)$. On the other hand, the bank vole increased significantly $\left(r_{23}=0.41, p<0.05\right)$ and substantially during competitor's removal, and at the end of the second year of removal, its density in the mouse removal-grid was almost two times higher than in the control-grid (see regression line in Fig. 2). During the post-removal period, these trends were reversed, and the populations decreased gradually and significantly, both in the wood mouse $\left(r_{30}=0.36, p<0.05\right)$ and in the bank vole $\left(r_{30}=0.49, p<0.01\right)$. The final population density for both species was similar to that before removal.

\section{Body condition}

Body mass varied throughout our experiment (Fig. 3). For both species and sexes, body mass decreased during the competitor removal period. The statistics for the regression lines shown in Fig. 3 for the removal period are: $r_{10}=0.17$, ns for males and $r_{11}=0.32$, ns for females of wood mouse; $r_{10}=0.64, p<0.05$ for males and $r_{11}=0.73, p<0.01$ for females of bank vole. On the other hand, during the post-removal period, body mass tended to increase again toward the initial value $\left(r_{18}=0.68, p<0.001\right.$ for males and $r_{19}=0.34$, ns for females of wood mouse; $r_{7}=$ 0.22 , ns for males and $r_{8}=0.04$, ns for females of bank vole). Therefore, body mass varied with trends (Fig. 3) that were opposite to the trends of the conspecific density (Fig. 2), ie mass decreased during the concomitant increase in conspecific abundance, and vice versa. Despite these general trends, however, no significant correlation was found between mass and conspecific density, for neither of the two rodents.

\section{Reproductive condition}

We considered the frequencies of mature males (with fully developed scrotal testes), receptive females (with open vagina), and reproductive females (pregnant or lactating), as indicators of the population reproductive condition. As with the other variables, we sought competitive effects by calculating the difference in frequency between the removal-grids and the control-grid. The frequency of the three categories did not show any trend that could be related to the experimental removal (Fig. 4). No significant correlation emerged between month and the frequency of any of the categories shown in Fig. 4, either during the removal period or the post-removal period.

\section{Habitat}

The three grids had similar habitat characteristics, with the only exception of the variance in overstorey density (Table 1, first row that contrasts all the capture points in the three grids). In the control-grid, the two mammals used very similar 

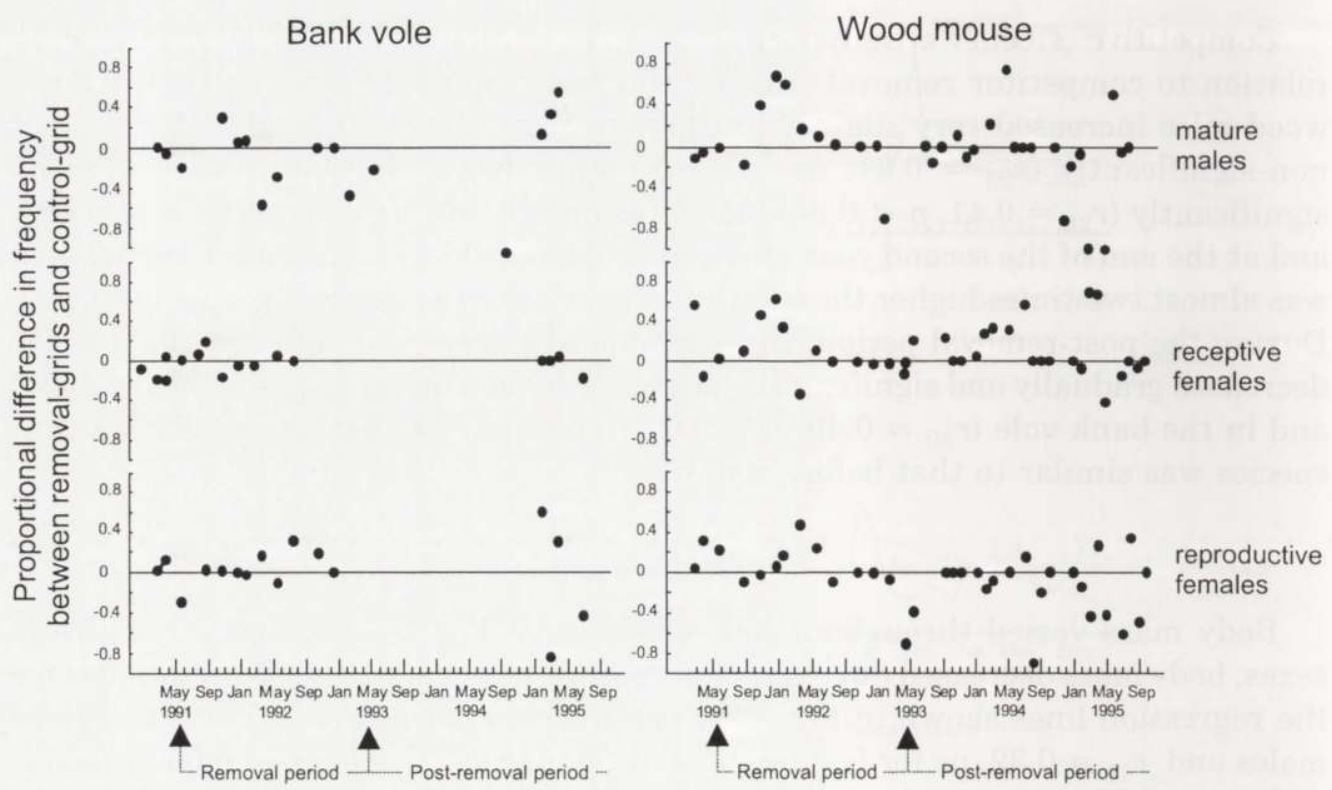

Fig. 4. Frequency of animals in three categories of reproductive status, compared between removal-grids and control-grid.

habitats, as can be seen from the similar plots in Fig. 5. This similarity is confirmed by the tests reported in Table 1 (second row, bank vole vs wood mouse in control-grid only). No significant difference emerged except for the larger understorey size at wood mouse capture points.

If a competitive effect were present, it would produce habitat shifts in relation to competitor removal. The main competitive effect would likely be an increased habitat breadth due to competitor removal, and this effect would be testable as an increase in variance of the measured habitat characteristics. No such effect was observed, either for the bank vole or the wood mouse, when their habitat use in removal-grids was compared among pre-removal, removal, and post-removal periods (Fig. 5 and the third and fourth rows in Table 1). On the other hand, many significant differences emerged for both rodents between control-grid and removal-grids (the two bottom rows in Table 1: contrasts limited only to the removal period). However, these differences do not support a competitive effect because the habitat shifts were non-directional. Bank voles increased their habitat breadth in the grid where their competitors were removed for 3 of the 5 characteristics with non-homogeneous variance, but decreased breadth for the other 2 characteristics, as shown in Fig. 5. Similarly, wood mice increased habitat breadth for 2 of the characteristics with non-homogeneous variance, but decreased breadth for the other 2 characteristics. These slight but significant differences in habitat use may have been caused by local differences in other characteristics of the environment. 
Table 1. Summary of the differences among means, and of the variance homogeneity, for the 6 micro-habitat characteristics. For each contrast, the upper row shows: one-way ANOVA $F, p<$ or ns (non-significant, 0.01 level), and the lower row shows: Levene test statistic, $p<$ or ns.

\begin{tabular}{|c|c|c|c|c|c|c|c|}
\hline \multirow[b]{2}{*}{ Contrasts } & \multirow[b]{2}{*}{ df } & \multicolumn{6}{|c|}{ Microhabitat characteristics } \\
\hline & & $\begin{array}{l}\text { Litter } \\
\text { depth }\end{array}$ & $\begin{array}{c}\text { Fallen } \\
\text { logs }\end{array}$ & $\begin{array}{l}\text { Under- } \\
\text { storey } \\
\text { density }\end{array}$ & $\begin{array}{l}\text { Under- } \\
\text { storey } \\
\text { size }\end{array}$ & $\begin{array}{l}\text { Over- } \\
\text { storey } \\
\text { density }\end{array}$ & $\begin{array}{l}\text { Over- } \\
\text { storey } \\
\text { size }\end{array}$ \\
\hline
\end{tabular}

(1) Three grids (control-grid, vole removal-grid, mouse removal-grid)

$\begin{array}{llllllll}\text { ANOVA } & 2,189 & \mathrm{~ns} & \mathrm{~ns} & \mathrm{~ns} & \mathrm{~ns} & \mathrm{~ns} & \mathrm{~ns} \\ \text { Levene test } & & \mathrm{ns} & \mathrm{ns} & \mathrm{ns} & \mathrm{ns} & 13.3,0.0001 & \mathrm{~ns}\end{array}$

(2) Bank vole vs wood mouse (control-grid only)

$\begin{array}{lllllcll}\text { ANOVA } & 1,930 & \mathrm{~ns} & \mathrm{~ns} & \mathrm{~ns} & 10.4,0.001 & \mathrm{~ns} & \mathrm{~ns} \\ \text { Levene test } & & \mathrm{ns} & \mathrm{ns} & \mathrm{ns} & \mathrm{ns} & \mathrm{ns} & \mathrm{ns}\end{array}$

(3) Bank vole in pre- vs post-removal periods (in mouse removal-grid only)

$\begin{array}{llllllll}\text { ANOVA } & 2,341 & \mathrm{~ns} & \mathrm{~ns} & \mathrm{~ns} & \mathrm{~ns} & \mathrm{~ns} & \mathrm{~ns} \\ \text { Levene test } & & \mathrm{ns} & \mathrm{ns} & \mathrm{ns} & \mathrm{ns} & 5.9,0.01 & \mathrm{~ns}\end{array}$

(4) Wood mouse in pre- vs post-removal periods (in vole removal-grid only)

$\begin{array}{llllllll}\text { ANOVA } & 2,573 & \mathrm{~ns} & \mathrm{~ns} & \mathrm{~ns} & \mathrm{~ns} & \mathrm{~ns} & \mathrm{~ns} \\ \text { Levene test } & & \mathrm{ns} & \mathrm{ns} & \mathrm{ns} & \mathrm{ns} & \mathrm{ns} & \mathrm{ns}\end{array}$

(5) Bank vole in control-grid vs mouse removal-grid (during removal period only)
ANOVA
1,382
$8.1,0.01$
$11.1,0.001 \quad 28.0,0.0001 \quad 8.5,0.01$
$12.5,0.001$
ns
Levene test
ns $\quad 54.5,0.0001 \quad 8.8,0.01$
$22.3,0.000123 .6,0.0001$
$9.7,0.01$

(6) Wood mouse in control-grid vs vole removal-grid (during removal period only)

$\begin{array}{lcccccccc}\text { ANOVA } & 1,546 & \text { ns } & \text { ns } & 7.5,0.01 & 11.9,0.001 & 13.0,0.001 & 39.8,0.0001 \\ \text { Levene test } & & \text { ns } & 7.6,0.01 & \text { ns } & 7.0,0.01 & 31.9,0.0001 & \text { ns }\end{array}$

\section{Discussion}

Evidence for competition between species of the genera Apodemus and Clethrionomys has been found in some studies. C. rutilus decreased in abundance during density peaks of $C$. rufocanus (Viitala 1984). A. sylvaticus displaced Micromys minutus during periods of food limitation in a manipulative experiment (Ylönen 1990). In a removal experiment, densities of $A$. argentatus were affected by those of A. speciosus, but the reverse effect did not occur (Sekijima and Soné 1994). On the other hand, inference from habitat use and population density showed that the role of competition between A. sylvaticus and A. mystacinus is probably very small (Abramsky 1981). No evidence for competition was found between A. sylvaticus and A. flavicollis, two very similar species that live syntopically in Britain. Despite the existence of spatial segregation due to aggression (Montgomery 1980b), neither evidence from population dynamics (Montgomery 1980a) nor from a removal 

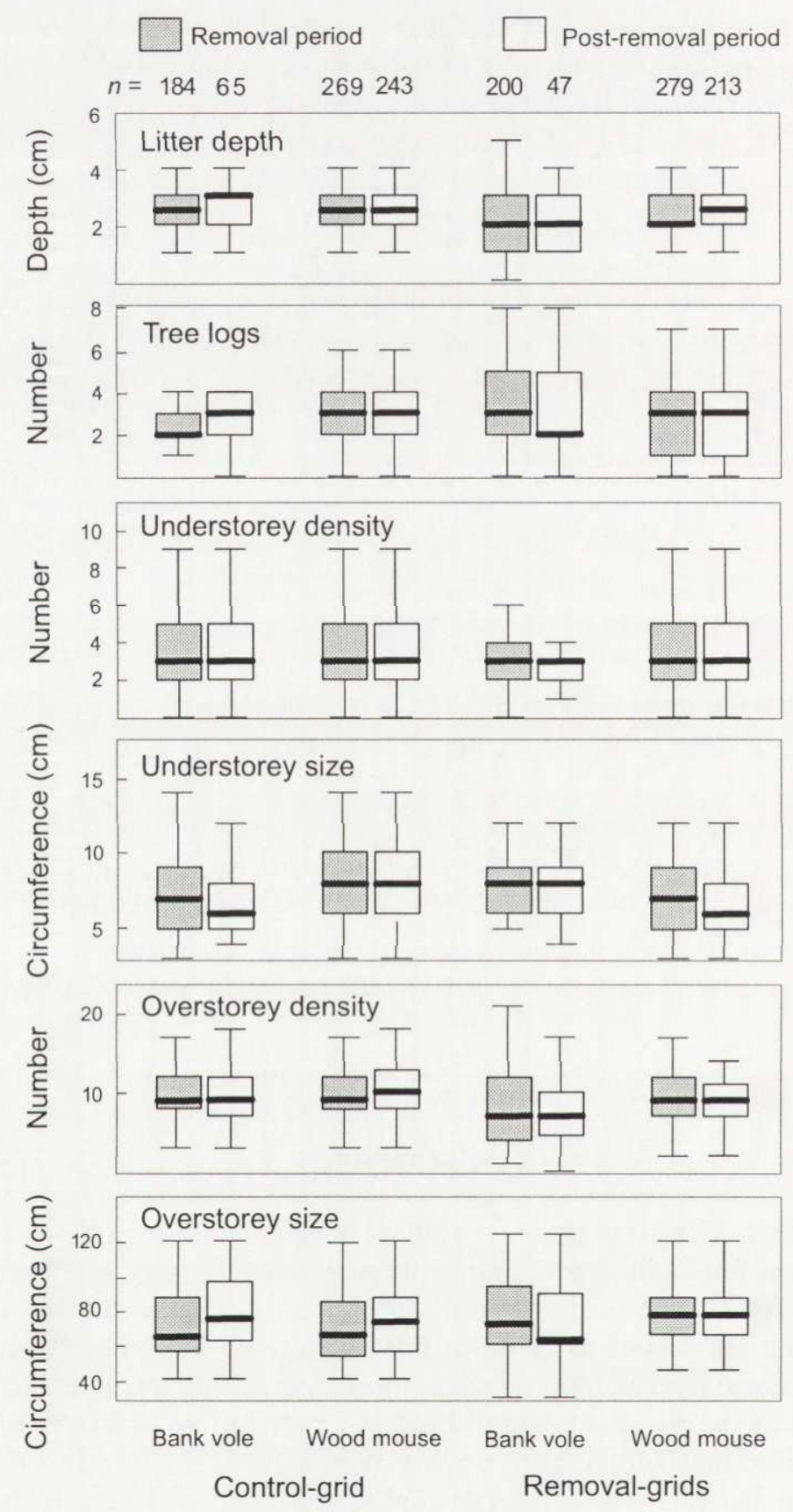

Fig. 5. Characteristics of microhabitats used by the two rodent species shown in box-and-whisker plots. Median values are indicated by thick horizontal lines, the boxes show the $25-75$ percentiles, and the thin lines mark the range except outliers, ie points distant $>1.5$ times box length. Numbers on top are sample sizes $(n)$. 
experiment (Montgomery 1981) supported the existence of competition, and it was concluded that ecological differences contribute to their stable coexistence.

Gurnell (1985) reviewed distribution, population, and habitat use of bank vole, wood mouse and yellow-necked mouse, and concluded that the available knowledge does not provide evidence of competition, although occasional competition may occur at high densities. The only previous removal experiment involving bank voles and wood mice showed that density and mortality of A. agrarius were affected by yellow-necked mice and bank voles (Gliwicz 1981, 1984), but this experiment lasted only 7 months and the competitors were not removed selectively.

During our experimental removal of the two rodent species, we found evidence that competitor removal affected strongly the population density of bank voles, but not, or very slightly, that of the wood mice. This effect was strongly asymmetrical because the increase in bank voles followed a competitor density reduction by one-third only, whereas the wood mouse did not increase despite its possible conpetitor had been experimentally reduced by two-thirds. Reproductive condition was not affected by changes in the density of competitors or of conspecifics. No habitat shifts were observed that could be related to competitor removal. The variations in body condition occurred with trends that were opposite to those of corspecific density, but without a significant correlation. The decrease in mass of bank vole males and females during competitor removal is difficult to explain, because weight dynamic in small rodents is not well understood. In bank voles, it is not clear whether the mass decrease in winter is due to changes in individual mass, or to changes in the age structure of the population and to a higher mortality of older and heavier individuals (Grodziński 1985). Changes in body mass are only partially linked to the annual fat cycle (Pucek 1973) and reflect a general dynamic of the gross body composition in water, protein and fat. The constant decrease in bocy mass of bank voles during the 3-year competitor removal, a period much longer than the average life span of the rodent, could be due to a variation in age stricture. In bank vole, competitor removal could make juveniles easier to capture, could increase colonisation by juveniles and subadults during pre-breeding dispersal, and could increase colonisation by lighter subordinate individuals during winter (efiects suggested for other rodents by Lidicker 1985). These effects could alter the age structure, and lower the mean mass of the bank vole population in the mouse renoval-grid.

We conclude that the bank vole was affected by the competitive presence of the word mouse, but only with respect to density. On the other hand, no significant conpetitive effects of the bank vole on the wood mouse were noted. Asymmetrical conpetition is not surprising, since three independent reviews (Lawton and Hassell 1981, Connell 1983, Schoener 1983) found respectively 61,66 , and $84 \%$ of studies on competition having discovered strongly asymmetrical interactions. But in the case of the wood mouse and the bank vole, such asymmetry is not easy to explain, sine the two species do not show a clear behavioural hierarchy (Lambin and Barchau 1989). 
Acknowledgements: We wish to thank all the students who carried out the field work, particularly C. Ricardo, S. Saraceni, P. Mella, P. Corsi, S. Grossi, L. Cornaggia. We also thank the Amministrazione Comunale di Pavia and the Lega Italiana Protezione Uccelli for access permission and facilities.

\section{References}

Abramsky Z. 1981. Habitat relationships and competition in two Mediterranean Apodemus spp. Oikos 36: $219-225$.

Abramsky Z. and Sellah C. 1982. Competition and the role of habitat selection in Gerbillus allenby and Meriones tristrami: a removal experiment. Ecology 63: 1242-1247.

Braude S. and Ciszek D. 1998. Survival of naked mole-rats marked by implantable transponders and toe-clipping. Mammalia 79: 360-363.

Busch M. and Kravetz F. O. 1992. Competitive interactions among rodents (Akodon azarae, Calomys laucha, Calomys musculinus and Oligoryzomys flavescens) in a two-habitat system. II. Effect of species removal. Mammalia 56: 541-554.

Canova L. 1992. Distribution and habitat preference of small mammals in a biotope of the North Italian plain. Bollettino di Zoologia 59: 417-421.

Canova L. 1993. Resource partitioning between the bank vole Clethrionomys glareolus and the wood mouse Apodemus sylvaticus in woodland habitats. Bollettino di Zoologia 60: 193-198.

Canova L. and Fasola M. 1991. Communities of small mammals in six biotopes of northern Italy. Acta Theriologica 36: 76-86.

Canova L. and Fasola M. 1993. Food habits and trophic relationships of small mammals in six habitats of the northern Po plain (Italy). Mammalia 57: 189-199.

Connell J. H. 1983. On the prevalence and relative importance of interspecific competition: evidence from field experiments. The American Naturalist 122: 661-696.

Corbet G. B. and Harris S. 1992. Handbook of British mammals. Blackwell, Oxford: 1-588.

Dooley J. L. and Dueser R. D. 1996. An experimental examination of nest-site segregation by two Peromyscus species. Ecology 71: 788-796.

Dueser R. D. and Shugart H. H. Jr 1978. Microhabitats in forest-floor small mammal fauna. Ecology 59: 89-98.

Galindo C. and Krebs C. J. 1985. Habitat use and abundance of deer mice: interactions with meadow voles and red-backed voles. Canadian Journal of Zoology 63: 1870-1879.

Geuse P. and Bachau V. 1985. Apodemus sylvaticus (Rodentia: Muridae) et Clethrionomys glareolus (Rodentia: Microtidae), competition or coexistence? Annales de la Societé royale de Zoologie du Belgique 115: 211-220.

Gilbert B. S. and Krebs C. J. 1984. Competition between Peromyscus maniculatus and other small rodents in the boreal forest of the southern Yukon territory. Acta Zoologica Fennica 172: 51-56.

Gliwicz J. 1981. Competitive interactions within a forest rodent community in central Poland. Oikos 37: $353-362$

Gliwicz J. 1984. Competition among forest rodents: effects of Apodemus flavicollis and Clethrionomys glareolus on A. agrarius. Acta Zoologica Fennica 172: 57-60.

Grant P. R. 1972. Interspecific competition among rodents. Annual Review of Ecology and Systematics 3: 79-106.

Grodziński W. 1985. Ecological energetics of bank voles and wood mice. [In: The ecology of woodland rodents. Bank voles and wood mice. J. R. Flowerdew, J. Gurnell and J. H. W. Gipps, eds]. Symposia of the Zoological Society of London 55: 169-188.

Gurevitch J., Morrow L., Wallace A. and Walsh J. S. 1992. A meta-analysis of competition in field experiments. The American Naturalist 140: 539-572.

Gurnell J. 1985. Woodland rodents communities. [In: The ecology of woodland rodents. J. R. Flowerdew, J. Gurnell and J. H. W. Gipps, eds]. Symposia of the Zoological Society of London 55: 377-411. 
Gurnell J. and Flowerdew J. R. 1990. Live trapping small mammals. A practical guide. Occasional Publications of the Mammal Society of London 3: 1-39.

Hansson L. 1985. The food of bank voles, wood mouse and yellow necked mouse. [In: The ecology of woodland rodents. J. R. Flowerdew, J. Gurnell and J. H. W. Gipps, eds]. Symposia of the Zoological Society of London 55: 141-168.

Heske E. J., Brown J. H. and Mistry S. 1994. Long-term experimental study of a Chihuahuan desert rodent community: 13 years of competition. Ecology 75: 438-445.

Kincaid W. B. and Cameron G. N. 1982. Effects of species removal on resource utilization in a Texas rodent comunity. Journal of Mammalogy 63: 229-235.

Lambin X. and Bauchau V. 1989. Contest competition between wood mice and bank voles: is there a winner? Acta Theriologica 34: 385-390.

Lawton J. H. and Hassell M. P. 1981. Asymmetrical competition in insects. Nature 289: 793-795.

Lidicker W. Z. 1985. Dispersal. [In: Biology of the New World Microtus. R. H. Tamarin, ed]. American Society of Mammalogy, Shippensburg, Pennsylvania. Special Publication no. 8: 420-454.

Montgomery W. I. 1980a. Population structure and dynamics of sympatric Apodemus species (Rodentia: Muridae). Journal of Zoology, London 192: 351-377.

Montgomery W. I. 1980b. Spatial segregation in sympatric populations of Apodemus sylvaticus and A. flavicollis (Rodentia: Muridae). Journal of Zoology, London 192: 379-401.

Montgomery W. I. 1981. A removal experiment with sympatric populations of Apodemus sylvaticus and A. flavicollis (Rodentia: Muridae). Oecologia 51: 123-132.

Munger J. C. and Brown J. H. 1981. Competition in desert rodents: an experiments with semipermeable exclosures. Science 211: 510-512.

Pucek M. 1973. Variability of fat and water content in two rodent species. Acta Theriologica 18: 57-80.

Pucek M. 1983. Habitat preferences. [In: Ecology of the bank vole. K. Petrusewicz, ed]. Acta Theriologica 28, Suppl. 1: 31-40.

Schoener T. W. 1983. Field experiments on interspecific competition. The American Naturalist 122: 240-285.

Scott D. E. and Dueser R. D. 1992. Habitat use by insular populations of Mus and Peromyscus: what is the role of competition? Journal of Animal Ecology 61: 329-338.

Sekijima T. and Soné K. 1994. Role of interspecific competition in the coexistence of Apodemus argenteus and A. speciosus (Rodentia, Muridae). Ecological Research 9: 237-244.

Thompson P. and Fox B. J. 1993. Asymmetric competition in Australian heatland rodents: a reciprocal removal experiment demonstrating the influence of size class structure. Oikos 67: 264-278.

Turner C. L. and Grant W. E. 1987. Effect of removal of Sigmodon hispidus on microhabitat utilization by Baiomys taylori and Reithrodontomys fulvescens. Journal of Mammalogy 68: 80-85.

Twigg J. I. 1978. Marking mammals by tissue removal. [In: Animal marking: recognition marking of animals in research. B. Stonehouse, ed]. MacMillan Press, London: 109-118.

Viitala J. 1984. The red vole, Clethrionomys rutilus (Pallas), as a subordinate member of the rodent community at Kilpisjärvi, Finnish Lapland. Acta Zoologica Fennica 172: 67-70.

White G. C., Anderson D. R., Burnham K. P. and Otis D. L. 1982. Capture-recapture and removal methods for sampling closed populations. Los Alamos National Laboratories, Los Alamos: 1-235.

Wójcik J. M. and Wołk K. 1985. The daily activity rhythm of two competitive rodents: Clethrionomys glareolus and Apodemus flavicollis. Acta Theriologica 30: 241-258.

Wolff J. O. and Dueser R. D. 1986. Noncompetitive coexistence between Peromyscus species and Clethrionomys gapperi. Canadian Field Naturalist 100: 186-191.

Ylönen H. 1990. Spatial avoidance between the bank vole Clethrionomys glareolus and the harvest mouse Micromys minutus: an experimental study. Annales Zoologici Fennici 27: 313-320.

Received 10 May 1999, accepted 30 September 1999. 